\title{
Significance of initial blood pressure and comorbidity for the efficacy of a fixed combination of an angiotensin receptor blocker and hydrochlorothiazide in clinical practice
}

\author{
This article was published in the following Dove Press journal: \\ Vascular Health and Risk Management \\ 12 November 2009 \\ Number of times this article has been viewed
}

\author{
Roland E Schmieder' \\ Markus Schwertfeger ${ }^{2}$ \\ Peter Bramlage ${ }^{3}$ \\ 'Department of Nephrology and \\ Hypertension, University Hospital of \\ Erlangen; Germany; ${ }^{2}$ Sanofi-Aventis \\ Deutschland GmbH, Berlin, Germany; \\ ${ }^{3}$ Institute of Cardiovascular \\ Pharmacology and Epidemiology, \\ Mahlow, Germany
}

Background: Two-thirds of all patients with arterial hypertension need drug combinations to achieve blood pressure (BP) goals. Fixed combinations have high efficacy and result in high patient compliance. $300 \mathrm{mg}$ irbesartan plus $25 \mathrm{mg}$ hydrochlorothiazide (HCTZ) has been investigated only in clinical trials but not in daily practice.

Methods: A multicenter, noninterventional, noncontrolled observational study with 8123 patients seen by 1604 physicians in daily practice. BP reduction (office measurements), co-morbid disease and tolerability were documented over a 6-month observational period.

Results: At mean baseline BP of $161 \pm 15 / 94 \pm 10 \mathrm{mmHg}$, administering of fixed combination resulted in a substantial BP reduction averaging $28 \pm 15 / 14 \pm 10 \mathrm{mmHg}(P<0.001)$. Decrease of systolic BP ran parallel with increasing systolic baseline BP (Spearman's Rho -0.731 ; $P<0.0001$; diastolic BP vs diastolic baseline BP Rho 0.740; $P<0.0001$ ), independent from patient characteristics (age, obesity, diabetes or nephropathy) but enhanced with short history of hypertension ( $P<0.0001$ vs long history), prior beta blockers $(P=0.001$ vs prior angiotensin receptor blockers [ARBs] $)$, prior calcium channel blockers $(P=0.046$ vs prior ARBs) and no prior medication $(P=0.012$ vs prior ARBs). High compliance $(>98 \%)$ and low incidence of adverse events $(0.66 \%)$ were documented.

Conclusions: The fixed combination of $300 \mathrm{mg}$ irbesartan with $25 \mathrm{mg} \mathrm{HCTZ}$ was efficacious and tolerable in an unselected patient population in primary care.

Keywords: hypertension, combination therapy, obesity, irbesartan, noninterventional study, diuretics

\section{Introduction}

Arterial hypertension is one of the commonest direct or indirect causes of increased cardiovascular morbidity and mortality worldwide. Its prevalence, for example, in the UK is $42 \%$, in Spain it is $47 \%$ and in Germany it is $55 \%$, while the rate in the US and in Canada is $28 \%$ and $27 \%$ respectively. ${ }^{1}$ Despite this strikingly high prevalence, the control rate of treated patients worldwide is low. Even in the US, only half of all treated patients achieve the target values (53.1\%), and in Germany the figure is only $33.6 \% .{ }^{2}$ An average reduction in systolic blood pressure of $2 \mathrm{mmHg}$ would in fact be associated with a $7 \%$ reduction in the stroke rate and a $10 \%$ reduction in ischemic heart diseases. ${ }^{3}$

Since many patients are not adequately controlled with monotherapy, nowadays the majority of patients are treated with a combination of 2 or more antihypertensive drugs.
Correspondence: Roland E Schmieder Department of Nephrology and Hypertensiology, University Hospital of Erlangen, Krankenhausstraße 12, 91054 Erlangen, Germany

$\mathrm{Tel}+49(9|3|) 8536245$

Fax +49 (913I) 8539209

Email roland.schmieder@uk-erlangen.de 
In Germany around one-third of patients receive monotherapy, one-third a combination of 2 substances and one-third a combination of 3 and more drugs (IMS Datamonitor 2003). The relevant guidelines ${ }^{4,5}$ recommend that combination therapy should be initiated early. The guidelines of the ESH/ESC $2007^{5}$ provide for the use of combination therapy if monotherapy is unsuccessful after the antihypertensive agent has been changed and in high dosages, or if patients with high cardiovascular risk present with blood pressure values which are $20 / 10 \mathrm{mmHg}$ above the target values. Nowadays the general recommendation for combination therapy is the combination of blockers of the renin-angiotensin system with thiazide diuretics or calcium antagonists. ${ }^{4,5}$ The advantage of a fixed dose combination is increased compliance, which ensures effective and lasting control of blood pressure.

Irbesartan has proved effective in reducing blood pressure in a number of clinical studies. ${ }^{6-8}$ With the fixed combination of $300 \mathrm{mg}$ irbesartan and $25 \mathrm{mg}$ hydrochlorothiazide (HCTZ), a high-dose combination has been available for some time now which achieves an even greater reduction in blood pressure. ${ }^{9}$ In addition, the RAPiHD study showed that the primary use of this combination in patients with severe hypertension is also effective and well tolerated. ${ }^{10}$

However, the results from randomized, controlled studies cannot be applied without further evaluation in everyday practice, because of their specific patient selection, close monitoring and generally short duration. The aim of the noninterventional study on hand was therefore to investigate the efficacy of the high-dose combination therapy under practice conditions in a non-selected patient population, and to document possible rare, so far undetected side effects of this fixed combination.

\section{Patients and methods}

The noninterventional, noncontrolled study was conducted with the aid of practice-based doctors throughout Germany (i-Control). These were a random sample of specialists in general medicine, internal medicine, cardiology and of practitioners from all the regions defined by the Institute of Medical Statistics (IMS). The study was registered in accordance with $\S 67$ (6) German Drugs Law (AMG) at the Federal Institute of Drugs and Medical Devices (BfArM) and at the National Association of Statutory Health Insurance Physicians (KBV).

\section{Issue investigated}

The investigation was conducted in order to document the efficacy and tolerability of the fixed combination of irbesartan 300 mg/HCTZ 25 mg (Coaprovel ${ }^{\mathrm{TM}} 300 \mathrm{mg} / 25 \mathrm{mg}$; sanofi-aventis Deutschland $\mathrm{GmbH}$, Berlin) in patients with arterial hypertension who had previously received pharmacotherapy and whose blood pressure was so far not controlled by other antihypertensives.

\section{Patients}

Patients were documented who at the time of the investigation were at least 18 years old, showed primary arterial hypertension with blood pressure values $\geq 140 / 90 \mathrm{mmHg}$ (diabetics $\geq 130 / 80 \mathrm{mmHg}$ ) and in whom previous pharmacotherapy of the hypertension had not resulted in the target blood pressure being achieved. In addition, the doctors had a free selection of patients within the scope of drug licensing (indications and contraindications), that is, no other inclusion and exclusion criteria were defined. They were also able to adjust the dosage of the concomitant medication throughout the duration of the study as desired.

\section{Documented variables}

At the enrolment visit, demographic data (age and gender) and also anamnestic data relating to cardiovascular risk factors were collected. In addition the weight, height, abdominal measurement (waist circumference), hip measurement, diseases related to the hypertension, previous antihypertensive therapy and concomitant medication, as well as a number of laboratory values for classification into certain risk groups were documented. At the optional check-up after 3 months, changes in blood pressure and medication as well as the occurrence of adverse events were documented. At the end of the observation after 6 months, a number of demographic data were again measured in the practice and blood pressure readings, medication and changes in the laboratory values were documented. In particular, the individual target blood pressure value for the documented patient was requested at the start of the investigation and it was verified that it had been achieved during the further course of the investigation.

\section{Execution}

The physicians were asked to document patients who were being treated with a combination of irbesartan $300 \mathrm{mg} / \mathrm{HCTZ}$ $25 \mathrm{mg}$ because of inadequately controlled primary arterial hypertension. The documentation forms were recorded by the Clinical Research Organization (CRO) factum - Gesellschaft für Statistik, wissenschaftiche Information und Kommunikation $\mathrm{mbH}$, Offenbach. The data in all documentation forms were examined for their plausibility. The documentation forms did not undergo comparison with the source documents for monitoring. The patients were recorded in pseudonymized 
form, ie, only the age and gender of the patient were entered in the documentation, and all data collected during the observation were treated confidentially. Data were electronically stored in accordance with data protection provisions. The fees for documentation activities were paid in accordance with the official scale of physicians' fees (Gebührenordnung für Ärzte, GOÄ).

\section{Adverse drug reactions}

Adverse drug reactions (ADRs) were explicitly asked about and recorded in detail (nature, date, duration, result, and causal relationship with the therapy). All physicians were asked to report serious adverse events to the pharmaceutical manufacturer immediately, which notified the BfArM in accordance with legal requirements.

\section{Statistics}

The statistical analysis was descriptively conducted, exploratively assessed, and then produced in tabular and graphic form. For categorical data absolute and relative frequencies and for steady variables average and standard deviation were calculated. The confidence intervals were calculated with the aid of the statistics program BIAS Version 8.4.6, publ. epsilon for theta of a binomial distribution; all other calculations were performed with the aid of the statistics program SPSS for Windows (Release 15.0). The statistical testing procedures conducted were the Mann-Whitney U test or the Kruskal-Wallis test for group differences in terms of changes in blood pressure. The Spearman's Rho was used for rank correlations (relationship of initial blood pressure to reduction in blood pressure). In order to be able to record rare ADRs, the number of cases was set at 8000 patients: this allows ADRs up to an incidence of $0.1 \%$ to be recorded with a probability of almost $100 \%$ and ADRs with an incidence of $0.01 \%$ with a probability of $55.1 \%$.

\section{Results}

A total of 8123 patients were included in the observation between November 2006 and January 2008 in 1604 centers (median: 5 patients per center).

The patients had an average age of $63.4 \pm 11.3$ years. $50.8 \%$ of them were male, and the patients had an average BMI of $29.4 \pm 4.9 \mathrm{~kg} / \mathrm{m}^{2}$. The initial blood pressure was $160.5 \pm 15.3 / 93.9 \pm 9.6 \mathrm{mmHg}$ with an average duration of hypertension of 8.4 years (Table 1). No concomitant diseases were present in $14.1 \%$ of the patients. The most common concomitant diseases were lipid metabolic disorders (53.7\%), diabetes mellitus (38.8\%) and metabolic syndrome (19.1\%).

\section{Medication}

During the observation phase all patients received $300 \mathrm{mg}$ irbesartan/25 mg HCT. In addition, some patients received further concomitant medication, comprising after 6 months $37.2 \%$ beta blockers, $25.3 \%$ calcium antagonists, $12.8 \%$ diuretics and $8.4 \%$ angiotensin-converting enzyme (ACE) inhibitors. Concomitant medication with alpha blockers or aldosterone antagonists was rare (Table 2). When making the decision in favor of a combination, the doctors most commonly switched from an ACE inhibitor medication (54.7\%), diuretics $(50.3 \%)$ and beta blockers $(49.0 \%)$.

\section{Antihypertensive effect according to baseline blood pressure}

After a follow-up observation of 6 months the systolic blood pressure was reduced on average by $27.9 \pm 15.2 \mathrm{mmHg}$ and the diastolic by $14.0 \pm 10.2 \mathrm{mmHg}$ compared with the initial blood pressure (in each case $P \leq 0.001$ compared with initial value). Based on a target value of $<140 / 90 \mathrm{mmHg}, 68.6 \%$ of the patients were normalized (systolic normalization $71.9 \%$, diastolic $88.3 \%$ ).

Figure 1A presents the reduction in systolic blood pressure achieved as a function of the initial systolic blood

Table I Patient characteristics at the start of therapy

\begin{tabular}{lll}
\hline Patient population & $\begin{array}{l}\text { Evaluable } \\
\text { data ( } \mathbf{n})\end{array}$ & Values \\
\hline Total number of patients & 8123 & \\
Men (\%) & 8037 & 50.8 \\
Age (years; mean \pm SD) & 7970 & $63.4 \pm 11.3$ \\
Body weight (kg; mean \pm SD) & 8083 & $85.8 \pm 16.0$ \\
BMI (kg/m²; mean \pm SD) & 8079 & $29.4 \pm 4.9$ \\
Smokers (\%) & 7589 & 22.8 \\
Blood pressure practice measurement & & \\
$\quad$ Systolic (mmHg; mean \pm SD) & 8096 & $160.5 \pm 15.3$ \\
$\quad$ Diastolic (mmHg; mean \pm SD) & 8094 & $93.9 \pm 9.6$ \\
Duration of hypertension & 7952 & $8.4 \pm 6.5$ \\
(years; average \pm SD) & & \\
Concomitant diseases ${ }^{\mathrm{a}}$ & & \\
Diabetes mellitus (\%) & 8102 & 38.8 \\
Peripheral arterial disease (\%) & 8102 & 6.3 \\
Diabetic nephropathy (\%) & 8102 & 4.8 \\
s/p myocardial infarction (\%) & 8102 & 6.9 \\
Lipid metabolic disorder (\%) & 8102 & 53.7 \\
Cardiac insufficiency (\%) & 8102 & 8.2 \\
s/p stroke (\%) & 8102 & 4.4 \\
No concomitant diseases (\%) & 8102 & 14.1 \\
\hline
\end{tabular}

aphysician defined, no specific testing.

Abbreviations: SD, standard deviation; BMI, body mass index; s/p, status post. 
Table 2 Therapy of arterial hypertension before and during observation

\begin{tabular}{|c|c|c|c|c|c|c|c|c|}
\hline & \multicolumn{2}{|c|}{$\begin{array}{l}\text { Before } \\
\text { the study }\end{array}$} & \multicolumn{2}{|c|}{$\begin{array}{l}\text { After start } \\
\text { of study }\end{array}$} & \multicolumn{2}{|c|}{$\begin{array}{l}\text { After } \\
3 \text { months }\end{array}$} & \multicolumn{2}{|c|}{$\begin{array}{l}\text { After } \\
6 \text { months }\end{array}$} \\
\hline & $\mathbf{n}$ & $\%$ & $\mathbf{n}$ & $\%$ & $\mathbf{n}$ & $\%$ & $\mathbf{n}$ & $\%$ \\
\hline ACE inhibitors & 4435 & 54.7 & 664 & 8.2 & 649 & 8.0 & 682 & 8.4 \\
\hline Beta blockers & 3976 & 49.0 & 2946 & 36.3 & 2945 & 36.3 & 3015 & 37.2 \\
\hline Diuretics & 4081 & 50.3 & 1068 & 13.2 & 996 & 12.3 & 1042 & 12.8 \\
\hline Calcium antagonists & 2569 & 31.7 & 1878 & 23.2 & 1931 & 23.8 & 2052 & 25.3 \\
\hline AT, blockers & 2159 & 26.6 & $-{ }^{\mathrm{a}}$ & $--^{\mathrm{a}}$ & $-^{\mathrm{a}}$ & $--^{a}$ & $-^{\mathrm{a}}$ & $-{ }^{*}$ \\
\hline Alpha blockers & 378 & 4.7 & 292 & 3.6 & 285 & 3.5 & 308 & 3.8 \\
\hline Aldosterone antagonists & 144 & 1.8 & 114 & 1.4 & 112 & 1.4 & 127 & 1.6 \\
\hline Irbesartan 300 mg/HCTZ 25 mg & $-{ }^{\mathrm{a}}$ & $--^{\mathrm{a}}$ & 8110 & 100.0 & 7855 & 96.9 & 7869 & 97.0 \\
\hline Other & 651 & 8.0 & 544 & 6.71 & 536 & 6.6 & 597 & 7.4 \\
\hline No medication & 104 & 1.3 & 0 & 0.0 & 0 & 0.0 & 9 & 0.1 \\
\hline I active substance group & 1779 & 21.9 & 0 & 0.0 & 25 & 0.3 & 51 & 0,6 \\
\hline 2 active substance group & 2745 & 33.8 & 3812 & 47.0 & 3642 & 44.9 & 3634 & 44.8 \\
\hline 3 active substance group & 2082 & 25.7 & 2679 & 33.0 & 2611 & 32.2 & 2,622 & 32.3 \\
\hline$>3$ active substance groups & 1310 & 16.2 & 1619 & 20.0 & 1629 & 20.1 & 1697 & 20.9 \\
\hline Not specified & 90 & 1.1 & 0 & 0.0 & 203 & 2.5 & 97 & 1.2 \\
\hline
\end{tabular}

alrbesartan/HCTZ was not asked about at the start and other AT, blockers were not asked about during the course of the study.

Abbreviations: ACE, angiotensin-converting enzyme; HCTZ, hydrochlorothiazide.

pressure (Rho $-0.731 ; P<0.0001)$. Figure $1 \mathrm{~B}$ presents the reduction in diastolic blood pressure achieved as a function of the diastolic initial blood pressure (Rho $-0.740 ; P<0.0001$ ). Figures $2 \mathrm{~A}$ and $\mathrm{B}$ shows the proportion of patients with normalized blood pressure as a function of the systolic/diastolic initial blood pressure. Here, too, a direct dependence of the frequency of normalization on the systolic initial blood pressure is shown: the higher the initial blood pressure, the lower was the normalization of both parameters of systolic and diastolic blood pressure.

\section{Antihypertensive efficacy according to patient characteristics}

Depending upon classification of the patient population based on the parameters of age, BMI, diabetes, duration of hypertension, nephropathy and previous therapy, the values for the reduction in systolic blood pressure ranged from -26.8 to $-30.2 \mathrm{mmHg}$. The reduction in blood pressure did not depend on patient characteristics such as age, obesity, diabetes and nephropathy. In contrast, the reduction in blood pressure in the case of short duration of the disease was increased vs long duration $(P<0.0001)$. Likewise blood pressure reduction in case of prior treatment with beta blockers $(P=0.001)$, calcium antagonists $(P=0.046)$ and no prior therapy $(P=0.012)$ was increased compared with angiotensin receptor blockers (Figure 3).

\section{Compliance}

Most (96.5\%) of the patients took the medication for the whole duration of the observational period $(2.1 \%$ not specified). Of the 110 patients $(1.36 \%)$ who terminated the therapy prematurely ( 22 because of adverse events), $44.6 \%$ were male and $17.3 \%$ were smokers. The average age of drop-outs was $64.7 \pm 12.5$ years, and the average BMI was $29.8 \pm 4.8 \mathrm{~kg} / \mathrm{m}^{2}$. Of the drop-outs, $88.2 \%$ had concomitant diseases, with lipid metabolic disorders at $47.3 \%$ and diabetes mellitus and obesity $\left(\mathrm{BMI}>30 \mathrm{~kg} / \mathrm{m}^{2}\right.$ ) each at $41.82 \%$ being most commonly represented.

\section{Tolerability of the therapy}

Adverse events occurred during the observation in a total of 54 patients $(0.66 \%)$. These were classified as ADRs in 35 patients $(0.43 \%)$ (Table 3$)$. The adverse event was rated as serious in a total of 12 patients ( 5 with ADRs).

ADRs are listed in Table 4. The serious ADRs included: transient ischemic attacks with signs of paralysis, ischemic optic neuropathy with visual impairment or blindness in the left eye, death of a patient as a result of carcinoma (the doctors considered a connection with the medication to be unlikely for the patients named above), myocardial infarction (unrelated or unlikely related), and also hypotension and vertigo (doctors' opinion: possible). 

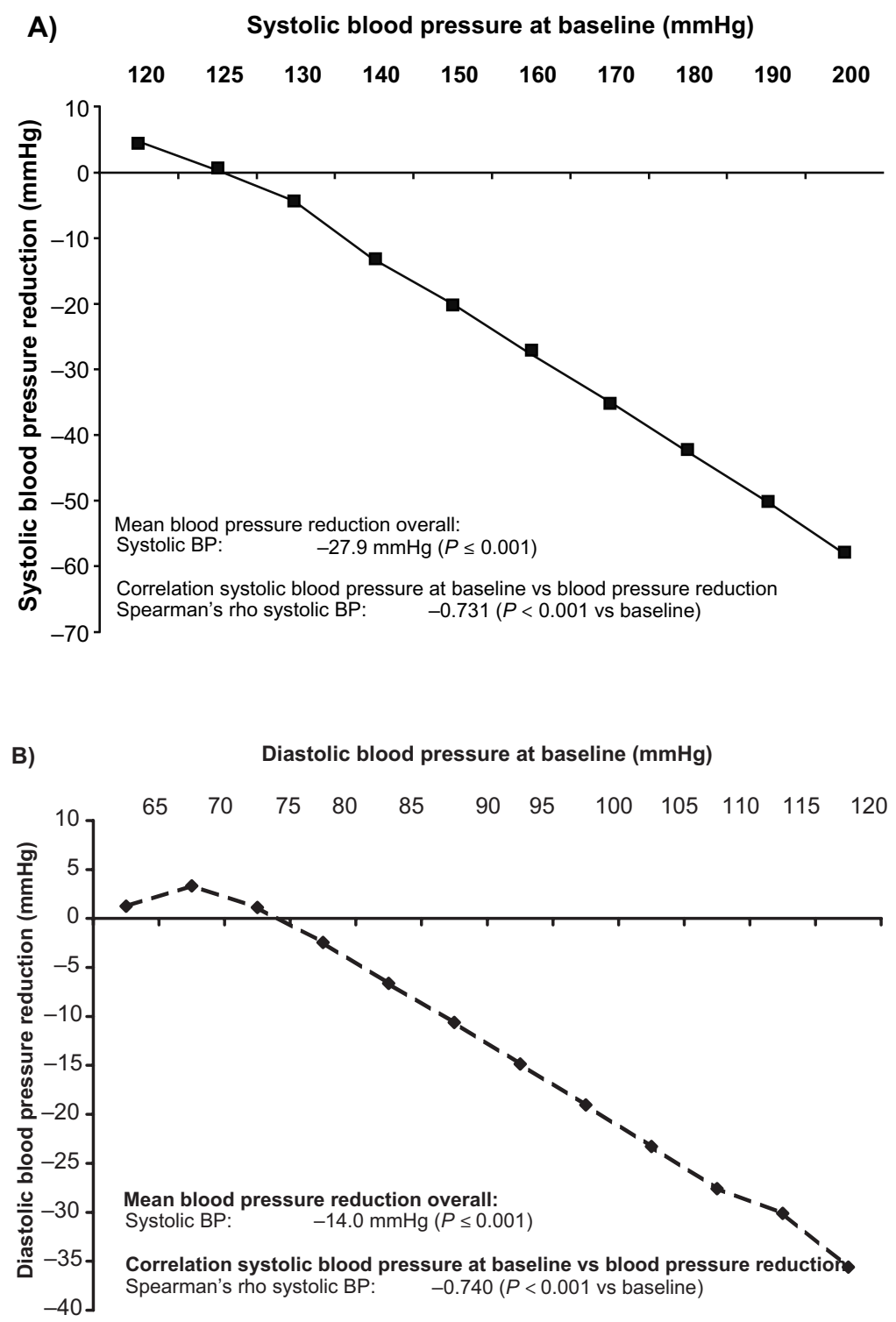

Figure I Reduction in blood pressure (BP) after 6 months as a function of the systolic $\mathbf{A}$ ) and diastolic B) initial blood pressure value.

\section{Discussion}

The patients documented in this noninterventional observational study were predominantly hypertensive patients with increased cardiovascular risk, whose blood pressure was so far not controlled, or only inadequately controlled, by monotherapy or low-dose combination therapy. Current guidelines recommend initial high-dose combination therapy for such patients. ${ }^{4,5}$ Observation of the use of irbesartan $300 \mathrm{mg} / \mathrm{HCTZ} 25 \mathrm{mg}$ over a period of 6 months produced the following important findings in this context: 1) The use of the fixed combination resulted in a clear further reduction in blood pressure $(27.9 / 14.0 \mathrm{mmHg}$, $P<0.001)$. 2) An almost linear increase in efficacy can be expected depending on the systolic initial blood pressure.
The higher the initial blood pressure, the greater the decrease in blood pressure. This might be significant especially for older patients with predominantly increased systolic blood pressure. 3) The efficacy is quantitatively not dependent on the presence of a range of concomitant diseases. 4) High compliance of $>98 \%$ because of a low incidence of adverse events $(0.66 \%)$ facilitates long-term adequate control of blood pressure.

\section{Efficacy of irbesartan $300 \mathrm{mg} / \mathrm{HCTZ}$ $25 \mathrm{mg}$ in everyday practice}

In 1999 Kochar et $\mathrm{al}^{9}$ tested the antihypertensive efficacy of the combination of irbesartan and HCTZ in various dosages for 8 weeks in a matrix study. At an average initial 
A)

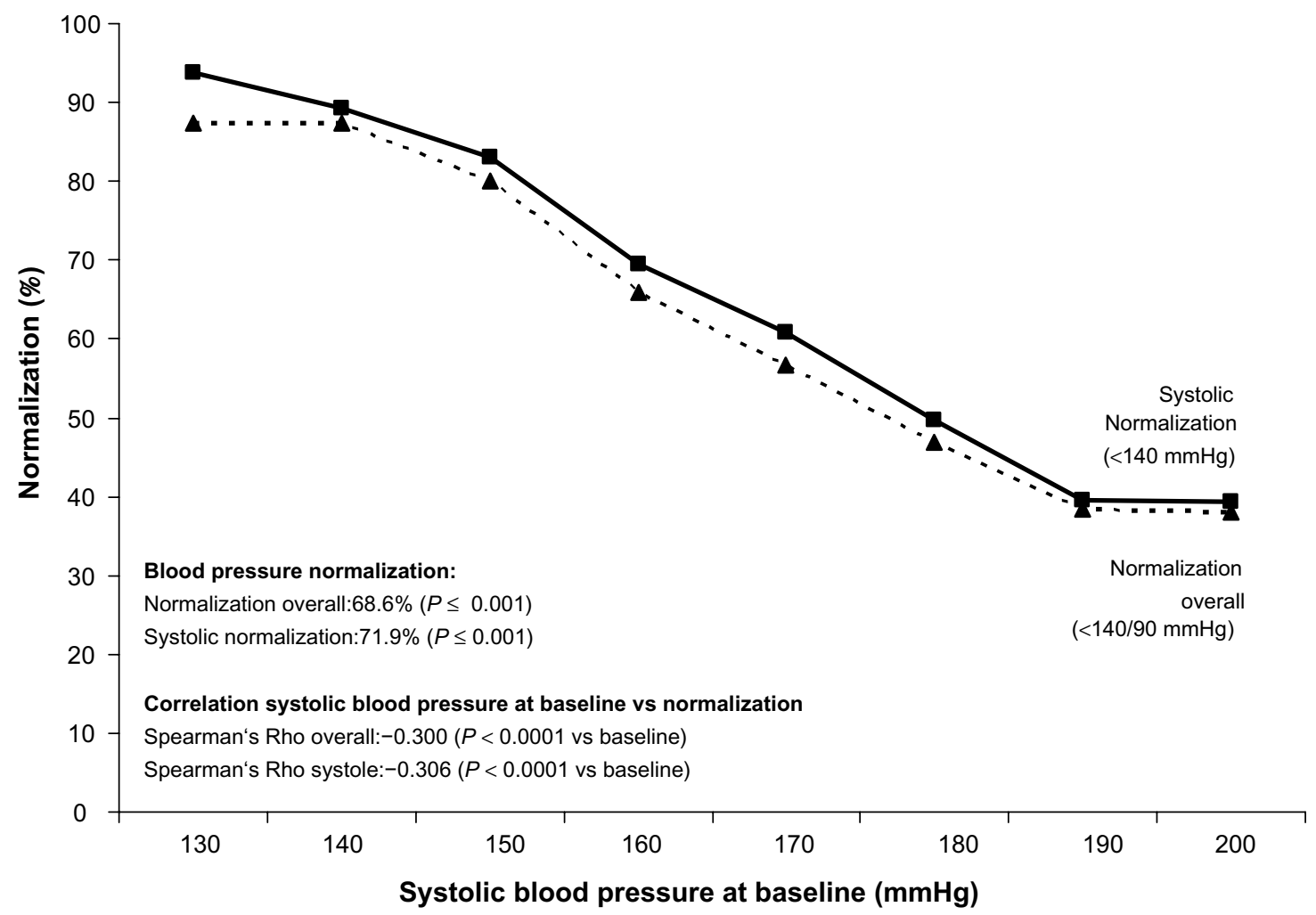

B)

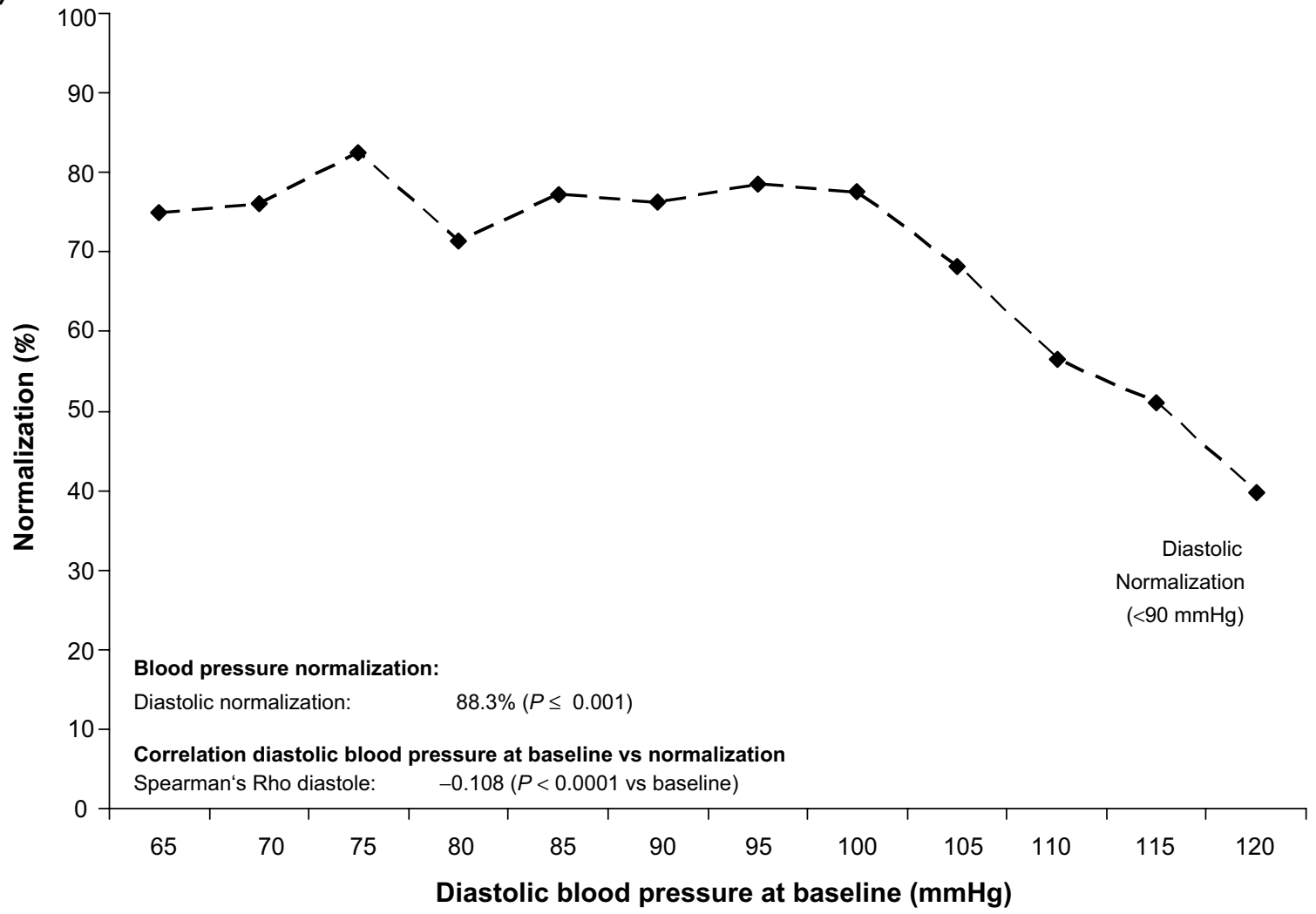

Figure 2 Normalization of blood pressure (BP) after 6 months in total and as a function of the systolic $\mathbf{A}$ ) and diastolic B) initial blood pressure value. 


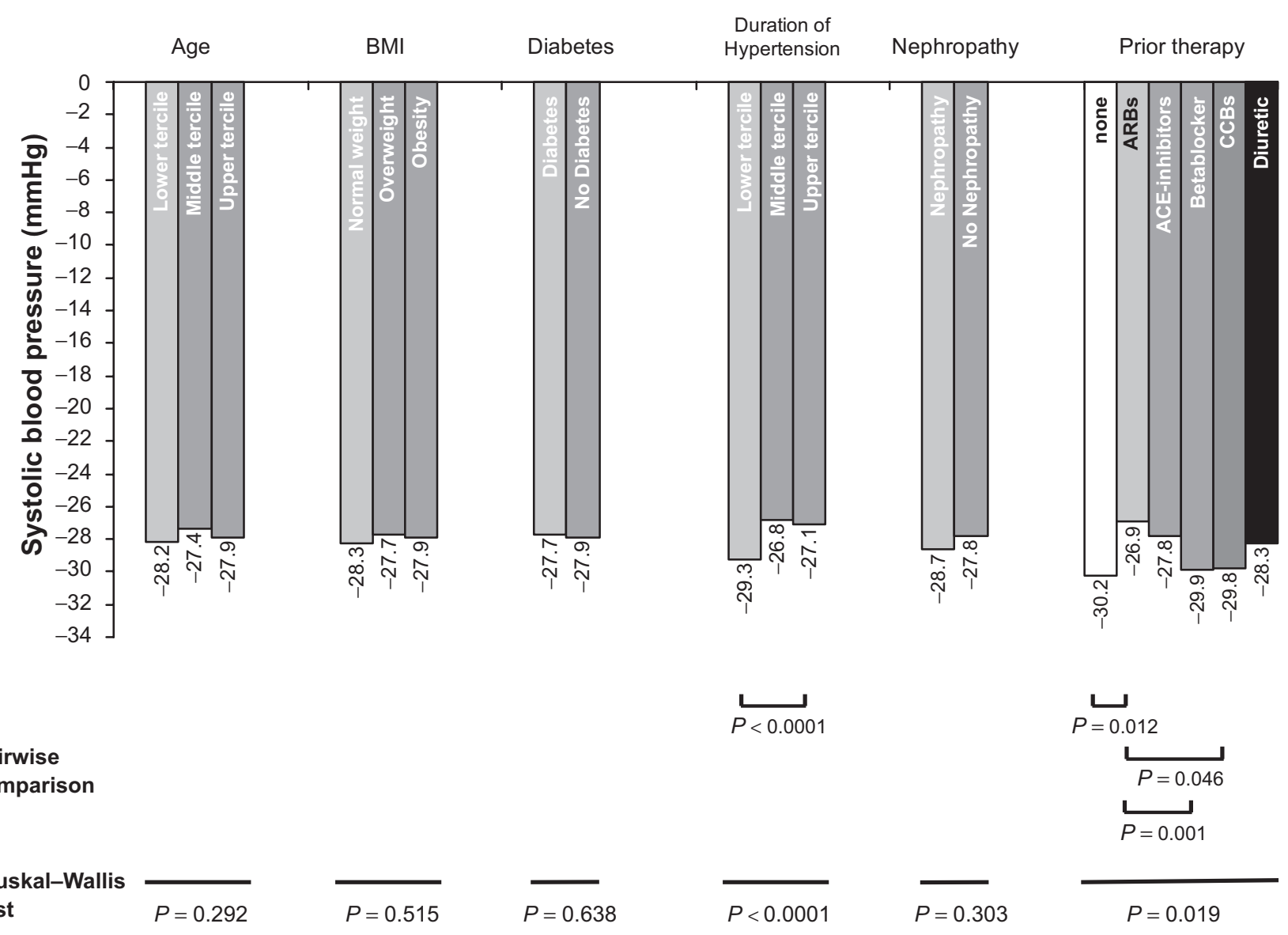

Figure 3 Reduction in systolic blood pressure (BP) $(\mathrm{mmHg})$ as a function of defined patient characteristics/previous medication. Use of the Kruskal-Wallis Test for differences within groups. Significant $P$-values for pairwise comparisons are indicated; other comparisons are not significant. Age: Lower tercile (LT) up to 58 years, middle tercile (MT) $>$ 58 to 69 years, upper tercile (UT) $>69$ years; body mass index (BMI): LT up to $25 \mathrm{~kg} / \mathrm{m}^{2}$, MT > 25 to $30 \mathrm{~kg} / \mathrm{m}^{2}$, UT > $30 \mathrm{~kg} / \mathrm{m}^{2}$; duration of hypertension: LT up to 5 years, MT $>5$ to 10 years, UT $>10$ years.

Abbreviations: $\mathrm{ACE}$, angiotensin-converting enzyme; $\mathrm{CCBs}$, calcium channel blockers.

Table 3 Number of patients with adverse events (AE) without causal relationship or adverse drug reactions (ADR) in the observation period

\begin{tabular}{lll}
\hline $\begin{array}{l}\text { Total population }(\mathbf{n}=\mathbf{8} \text { I 23) } \\
\text { (multiple answers possible) }\end{array}$ & $\mathbf{n}$ & $\%$ \\
\hline Patients without AE & 8,056 & 99.18 \\
Patients with AE & 54 & 0.66 \\
$\quad$ Serious & 12 & 0.15 \\
$\quad$ Not serious & 43 & 0.53 \\
Therapy discontinued & 22 & 0.27 \\
because of AE & 35 & \\
Patients with ADR & 5 & 0.43 \\
Serious & 30 & 0.06 \\
Not serious & 13 & 0.37 \\
No verification possible & & 0.16 \\
\hline
\end{tabular}

Notes: Binominal confidence interval calculated according to BIAS Version 8.4.6. blood pressure of $151 \pm 14.7 / 100 \pm 4.2 \mathrm{mmHg}$, an average reduction in blood pressure of $23.1 \pm 15.0 / 14.4 \pm 8.0$ was achieved in this study with irbesartan $300 \mathrm{mg} / \mathrm{HCTZ} 25 \mathrm{mg}$. In a further study of Neutel, patients with severe hypertension (initial blood pressure 171.5/77.4 $\mathrm{mmHg}$ ) were treated for 7 weeks with the irbesartan/HCTZ high-dose combination. ${ }^{10}$ A reduction in blood pressure of $31.7 / 24.5 \mathrm{mmHg}$ was achieved. The results of the noninterventional study supplement these data and findings with data from everyday clinical practice. The reduction in systolic blood pressure extrapolated from the clinical studies for this initial blood pressure is 27.4; in fact an average reduction in blood pressure of $27.9 \mathrm{mmHg}$ was achieved. Because of the lack of a wash-out phase, the lack of guidance for the changeover and the lack of concomitant medication, in theory a lower reduction in blood pressure would be expected, but this was not confirmed in the study. 
RAPiHD severe ${ }^{14}$

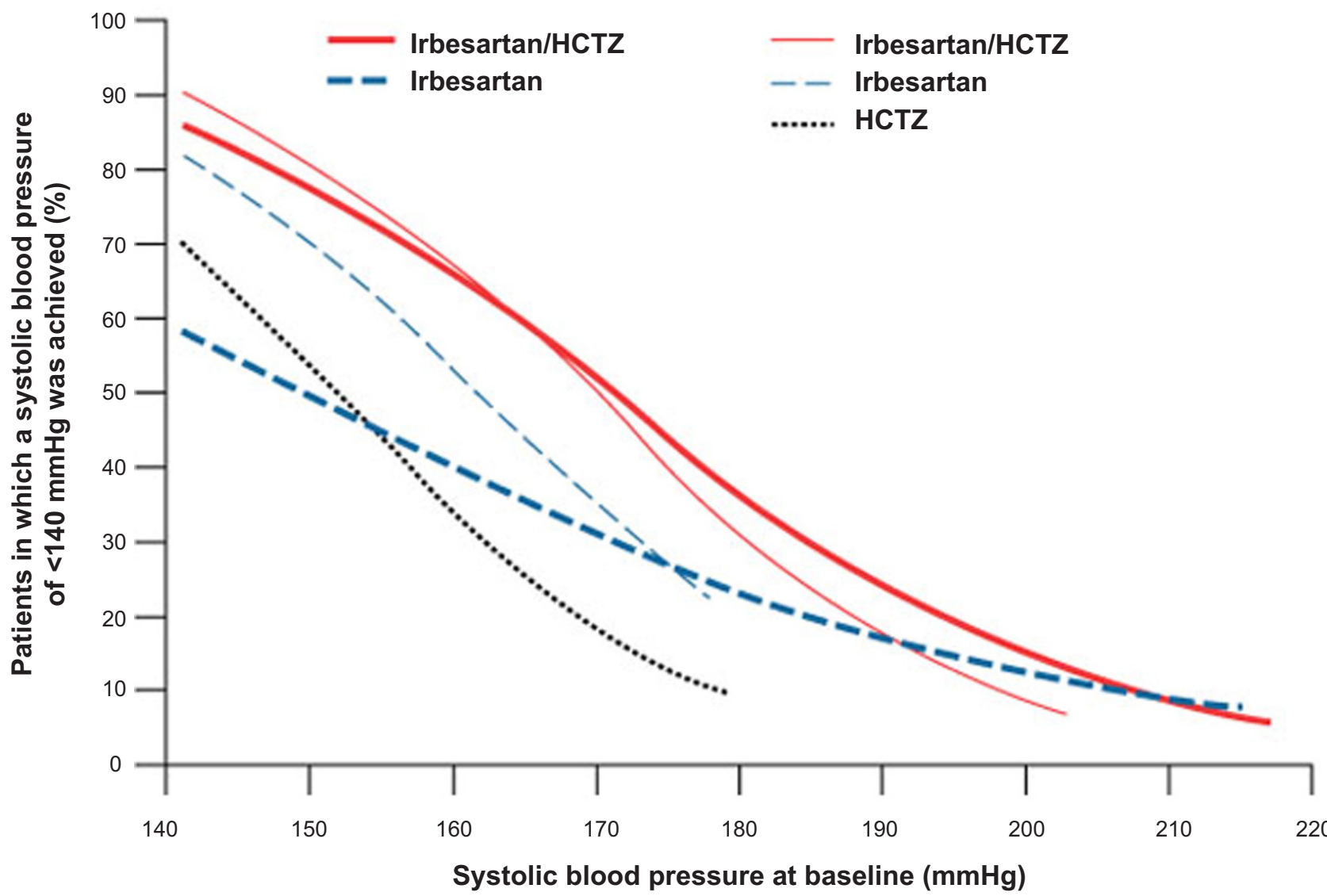

Figure 4 Systolic normalization $\left(<140 \mathrm{mmHg}\right.$ ) according to systolic initial blood pressure value in the studies RAPiHD severe ${ }^{10}$ and RAPiHD moderate ${ }^{24}$ (after Franklin) ${ }^{18}$. RAPiHD severe was a 7-week trial in patients with severe hypertension (seated DBP [SeDBP] $\geq 110 \mathrm{mmHg}$ ). Eligible patients entered a 7-day single-blind placebo lead-in period. Patients with SeDBP $\geq 110 \mathrm{mmHg}$ at 2 consecutive visits during the lead-in period were randomized in a 2:I ratio to irbesartan/HCTZ I50/I2.5 mg fixed-dose combination therapy force-titrated to $300 / 25 \mathrm{mg}$ after week I or irbesartan $150 \mathrm{mg}$ monotherapy force-titrated to $300 \mathrm{mg}$ after week I. RAPiHD moderate was a I2-week trial in patients with moderate hypertension (seated SBP [SeSBP] 160-180 mmHg or SeDBP 100-I I0 mm Hg). Eligible patients entered a 21 -day single-blind placebo wash-out period before randomization in a 3:I:I ratio to irbesartan/HCTZ I50/I2.5 mg fixed-dose combination therapy force-titrated to $300 / 25 \mathrm{mg}$ after week 2 , irbesartan I50 mg monotherapy force-titrated to $300 \mathrm{mg}$ after week 2, or HCTZ $12.5 \mathrm{mg}$ monotherapy force-titrated to $25 \mathrm{mg}$ after week 2.

Abbreviation: HCTZ, hydrochlorothiazide.

To date there are no direct comparisons available of the relative efficacy of irbesartan $300 \mathrm{mg} / \mathrm{HCTZ} 25 \mathrm{mg}$ with fixed combinations of other sartans with $25 \mathrm{mg}$ HCTZ. However the relative efficacy from the comparison of substances in monotherapy ${ }^{7,8,11}$ is generally maintained for the corresponding combinations with HCTZ. ${ }^{12,13}$ These studies showed a greater reduction in blood pressure from $150 \mathrm{mg}$ irbesartan compared with $50 \mathrm{mg}$ losartan ${ }^{7,11,13}$ both with and without HCTZ. In a study with losartan $100 \mathrm{mg} / \mathrm{HCTZ} 25 \mathrm{mg}$, a reduction in blood pressure of $24.0 / 11.8 \mathrm{mmHg}$ was achieved at an initial blood pressure of $160.8 / 94.4 \mathrm{mmHg} .{ }^{14}$ These data are largely comparable with the data on hand (reduction in blood pressure 27.9/14.0 at an initial blood pressure of $160.5 / 93.9 \mathrm{mmHg}$ ), even if they are nominally higher. Other data relating to the efficacy of high-dose fixed combinations in everyday practice are not yet available.

\section{Predictor of reduction in blood pressure}

The antihypertensive efficacy of substances is quite decisively dependent on the blood pressure values at the start of the study. ${ }^{15} \mathrm{~A}$ range of studies has shown that the higher the initial value, the higher the achievable reduction in blood pressure $^{16,17}$ or the more common is the normalization of blood pressure after the start of therapy ${ }^{16-19}$ (see also Figure 4). This might be related to a regression to the mean phenomenon in single patients but certainly not in the majority of patients in this study of more than 8123 patients. Thus the average reduction in blood pressure in the study of Schühlen et al was 26.8/13.5 $\mathrm{mmHg}$, and in patients with severe hypertension 
Table 4 Adverse drug reactions (ADR) coded according to MedDRA $^{\circledR}$ Version 10.0

\begin{tabular}{lll}
\hline $\begin{array}{l}\text { Total population }(\mathbf{n}=\mathbf{8} \text { I 23) } \\
\text { MedDRA }{ }^{\circledR} \text { primary System }\end{array}$ & $\mathbf{n}$ & $\%$ \\
Organ Classes (SOC) & & \\
\hline Patients with ADR & 35 & 0.43 \\
Cardiac disorders & 2 & 0.02 \\
Eye disorders & $\mathrm{I}$ & 0.01 \\
Gastrointestinal disorders & 5 & 0.06 \\
General disorders and administration site conditions & 5 & 0.06 \\
Investigations & $\mathrm{I}$ & 0.01 \\
Metabolism and nutrition disorders & 2 & 0.02 \\
Musculoskeletal and connective tissue disorders & $\mathrm{I}$ & 0.01 \\
Nervous system disorders & 15 & 0.18 \\
Renal and urinary disorders & $\mathrm{I}$ & 0.01 \\
Respiratory, thoracic and mediastinal disorders & 4 & 0.05 \\
Skin and subcutaneous tissue disorders & 4 & 0.05 \\
Vascular disorders & 6 & 0.07 \\
Patients without ADR & 8075 & 99.41 \\
Verification not possible & 13 & 0.16 \\
Total & $\mathbf{8 I 2 3}$ & $\mathbf{1 0 0 . 0}$ \\
\hline
\end{tabular}

$(41.7 / 20.5 \mathrm{mmHg})$. In particular, an analysis of the prediction of the reduction in blood pressure in the INCLUSIVE study showed that an increase of $1 \mathrm{mmHg}$ in the systolic initial blood pressure can predict an additional reduction of $0.9 \pm 0.1 \mathrm{mmHg}$ in the systolic blood pressure..$^{20}$ The study presented here also shows a linear relationship between the systolic/diastolic blood pressure at the start of the study and the achievable reduction in blood pressure (Figure 1). On the other hand, the incidence of hypotension in the study on hand is rare, even in higher dosages. Clear effects on blood pressure are not expected in normotensive patients. Out of over 8123 patients, only 13 terminated the therapy because of vertigo or hypotension.

The analysis of the study on hand continued to show no dependency of the reduction in blood pressure on age, diabetes, weight and nephropathy. These results therefore confirm previous analyses of the efficacy of irbesartan/HCTZ in various patient populations. ${ }^{10,21-23}$ In contrast, the predictor analysis of the INCLUSIVE study reported that higher reductions in blood pressure were to be expected in patients with higher initial blood pressure values (see above), type 2 diabetes $(+5.0 \mathrm{mmHg})$, with statin intake $(+2.1 \mathrm{mmHg})$ and for women $(+3 \mathrm{mmHg}){ }^{20}$

\section{Compliance and tolerability}

Irbesartan is well tolerated both in monotherapy and also in combination with HCTZ. In a pooled analysis ${ }^{18}$ of the two
RAPiHD studies (moderate and severe), ${ }^{10,24} 37.0 \%$ adverse events occurred, which were ascribed to the medication in $12.5 \%$ of the patients $(0.9 \%$ serious $)$. These figures were only slightly raised compared with irbesartan monotherapy. In the healthcare study on hand, $<1 \%$ adverse events were reported; $0.43 \%$ were linked to the medication $(0.06 \%$ serious).

\section{Conclusions}

The fixed combination of $300 \mathrm{mg}$ irbesartan and $25 \mathrm{mg} \mathrm{HCTZ}$ is effective and well tolerated. The effect increases depending on the initial blood pressure, but is largely independent of various patient characteristics. This study thus confirms the data from previous clinical studies for a nonselected patient group in everyday practice.

\section{Acknowledgments}

We wish to thank all the doctors who took part in this study and their assistants for participating in this study. Our special thanks also to the Clinical Research Organization (CRO) factum - Gesellschaft für Statistik, wissenschaftliche Information und Kommunikation mbH, Offenbach.

\section{Disclosures}

The study was conducted by sanofi-aventis Deutschland $\mathrm{GmbH}$. RES declares to have received research support and lecture honoria from AstraZeneca, Boehringer Ingelheim, Bristol Myers Squibb, Novartis, sanofi-aventis, and Takeda. PB declares to have received research support and lecture honoria from sanofi-aventis, Daiichi Sankyo, Takeda. MS is an employee of sanofi-aventis.

\section{References}

1. Wolf-Maier K, Cooper RS, Banegas JR, et al. Hypertension prevalence and blood pressure levels in 6 European countries, Canada, and the United States. JAMA. 2003;289(18):2363-2369.

2. Kearney PM, Whelton M, Reynolds K, Whelton PK, He J. Worldwide prevalence of hypertension: a systematic review. J Hypertens. 2004;22(1):11-19.

3. Lewington S, Clarke R, Qizilbash N, Peto R, Collins R. Age-specific relevance of usual blood pressure to vascular mortality: a meta-analysis of individual data for one million adults in 61 prospective studies. Lancet. 2002;360(9349):1903-1913.

4. Leitlinien zur Behandlung der arteriellen Hypertonie 2008. Deutsche Hochdruckliga, 2008.

5. Mancia G, De Backer G, Dominiczak A, et al. Guidelines for the Management of Arterial Hypertension: The Task Force for the Management of Arterial Hypertension of the European Society of Hypertension (ESH) and of the European Society of Cardiology (ESC). J Hypertens. 2007;25(6):1105-1187.

6. Bobrie G, Delonca J, Moulin C, Giacomino A, Postel-Vinay N, Asmar R. A home blood pressure monitoring study comparing the antihypertensive efficacy of two angiotensin II receptor antagonist fixed combinations. Am J Hypertens. 2005;18(11):1482-1488. 
7. Kassler-Taub K, Littlejohn T, Elliott W, Ruddy T, Adler E. Comparative efficacy of two angiotensin II receptor antagonists, irbesartan and losartan in mild-to-moderate hypertension. Irbesartan/Losartan Study Investigators. Am J Hypertens. 1998;11(4 Pt 1):445-453.

8. Mancia G, Korlipara K, van Rossum P, Villa G, Silvert B. An ambulatory blood pressure monitoring study of the comparative antihypertensive efficacy of two angiotensin II receptor antagonists, irbesartan and valsartan. Blood Press Monit. 2002;7(2):135-142.

9. Kochar M, Guthrie R, Triscari J, Kassler-Taub K, Reeves RA. Matrix study of irbesartan with hydrochlorothiazide in mild-to-moderate hypertension. Am J Hypertens. 1999;12(8 Pt 1):797-805.

10. Neutel JM, Franklin SS, Oparil S, Bhaumik A, Ptaszynska A, Lapuerta P. Efficacy and safety of irbesartan/HCTZ combination therapy as initial treatment for rapid control of severe hypertension. J Clin Hypertens (Greenwich). 2006;8(12):850-857.

11. Oparil S, Guthrie R, Lewin AJ, et al. An elective-titration study of the comparative effectiveness of two angiotensin II-receptor blockers, irbesartan and losartan. Irbesartan/Losartan Study Investigators. Clin Ther. 1998;20(3):398-409.

12. Bobrie G, Delonca J, Moulin C, Giacomino A, Postel-Vinay N, Asmar R. A home blood pressure monitoring study comparing the antihypertensive efficacy of two angiotensin II receptor antagonist fixed combinations. Am J Hypertens. 2005;18(11):1482-1488.

13. Neutel JM, Smith D. Ambulatory blood pressure comparison of the anti-hypertensive efficacy of fixed combinations of irbesartan/ hydrochlorothiazide and losartan/hydrochlorothiazide in patients with mild-to-moderate hypertension. J Int Med Res. 2005;33(6):620-631.

14. Forster A, Smolka W, Jung C, Bestehorn K. [Fixed-combination of losartan/hydrochlorothiazide $100 \mathrm{mg} / 25 \mathrm{mg}$. Tolerability and efficacy on blood pressure measured in the practice and for 24 hours]. $M M W$ Fortschritte der Medizin. 2007;149(Suppl 3):111-118.

15. Bramlage P. Fixed combination of irbesartan and hydrochlorothiazide in the management of hypertension. Vasc Health Risk Manag. 2009;5:213-224.

16. Schuhlen H, Abts M, Kastrati D. [Intensive blood pressure reduction in patients with increased cardiovascular risk with high-dose combination therapy of $160 \mathrm{mg}$ valsartan plus $25 \mathrm{mg}$ hydrochlorothiazide. Results of the MACHT II observational study]. Herz. 2007;32(5):419-425.
17. Schrader J, Bramlage P, Luders S, Thoenes M, Schirmer A, Paar DW. BP goal achievement in patients with uncontrolled hypertension: results of the treat-to-target post-marketing survey with irbesartan. Clin Drug Investig. 2007;27(11):783-796.

18. Franklin S, Lapuerta P, Cox D, Donovan M. Initial combination therapy with irbesartan/hydrochlorothiazide for hypertension: an analysis of the relationship between baseline blood pressure and the need for combination therapy. J Clin Hypertens (Greenwich). 2007; 9(12 Suppl 5):15-22.

19. Schmieder RE, Krekler M. [Observational study of blood pressure control and microalbuminuria in type 2 diabetics on irbesartan or irbesartan/HCTZ]. MMW Fortschr Med. 2005;147(Suppl 3):97-101.

20. Saunders E, Cable G, Neutel J. Predictors of blood pressure response to angiotensin receptor blocker/diuretic combination therapy: a secondary analysis of the irbesartan/hydrochlorothiazide blood pressure reductions in diverse patient populations (INCLUSIVE) study. J Clin Hypertens (Greenwich). 2008;10(1):27-33.

21. Sowers JR, Neutel JM, Saunders E, et al. Antihypertensive efficacy of Irbesartan/HCTZ in men and women with the metabolic syndrome and type 2 diabetes. J Clin Hypertens (Greenwich). 2006;8(7):470-480.

22. Cushman WC, Neutel JM, Saunders E, et al. Efficacy and safety of fixed combinations of irbesartan/hydrochlorothiazide in older vs younger patients with hypertension uncontrolled with monotherapy. Am J Geriatr Cardiol. 2008;17(1):27-36.

23. Weir MR, Neutel JM, Bhaumik A, De Obaldia ME, Lapuerta P. The efficacy and safety of initial use of irbesartan/hydrochlorothiazide fixed-dose combination in hypertensive patients with and without high cardiovascular risk. J Clin Hypertens (Greenwich). 2007; 9(12 Suppl 5):23-30.

24. Neutel JM, Franklin SS, Lapuerta P, Bhaumik A, Ptaszynska A. A comparison of the efficacy and safety of irbesartan/HCTZ combination therapy with irbesartan and HCTZ monotherapy in the treatment of moderate hypertension. J Hum Hypertens. 2008;22(4):266-274.
Vascular Health and Risk Management

\section{Publish your work in this journal}

Vascular Health and Risk Management is an international, peerreviewed journal of therapeutics and risk management, focusing on concise rapid reporting of clinical studies on the processes involved in the maintenance of vascular health; the monitoring, prevention and treatment of vascular disease and its sequelae; and the involvement of

\section{Dovepress}

metabolic disorders, particularly diabetes. This journal is indexed on PubMed Central and MedLine. The manuscript management system is completely online and includes a very quick and fair peer-review system, which is all easy to use. Visit http://www.dovepress.com/ testimonials.php to read real quotes from published authors. 